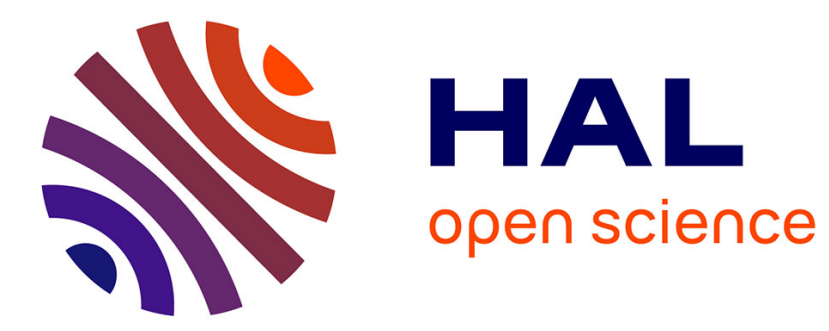

\title{
Optimized annular triode ion pump for experimental areas in the LHC
}

M. Busso, A. Chatelain, Christian Girard, D. Flakowski, S. Ivaldi, J. Knaster, J. M. Laurent, I. Monteiro, A. Rossi, R. Veness

\section{- To cite this version:}

M. Busso, A. Chatelain, Christian Girard, D. Flakowski, S. Ivaldi, et al.. Optimized annular triode ion pump for experimental areas in the LHC. 8th European Vacuum Conference, Jun 2003, Berlin. in2p3-00025580

\author{
HAL Id: in2p3-00025580 \\ https://hal.in2p3.fr/in2p3-00025580
}

Submitted on 7 Feb 2006

HAL is a multi-disciplinary open access archive for the deposit and dissemination of scientific research documents, whether they are published or not. The documents may come from teaching and research institutions in France or abroad, or from public or private research centers.
L'archive ouverte pluridisciplinaire HAL, est destinée au dépôt et à la diffusion de documents scientifiques de niveau recherche, publiés ou non, émanant des établissements d'enseignement et de recherche français ou étrangers, des laboratoires publics ou privés. 


\title{
EUROPEAN ORGANIZATION FOR NUCLEAR RESEARCH \\ European Laboratory for Particle Physics
}

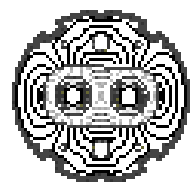

Large Hadron Collider Project

LHC Project Report 670

\section{OPTIMIZED ANNULAR TRIODE ION PUMP FOR EXPERIMENTAL AREAS IN THE LHC}

\author{
M. Busso ${ }^{1}$, A. Chatelaine ${ }^{2}$, C. Girard ${ }^{2}$, D. Flakowski ${ }^{3}{ }^{\text {S. Ivaldi }}{ }^{1}$, J. Knaster ${ }^{3}$ J M. Laurent ${ }^{3}$, \\ I. Monteiro' ${ }^{2}$ A. Rossi ${ }^{3}$, R. Veness ${ }^{3}$
}

\begin{abstract}
The LHC will be the world next generation accelerator to be operational in 2007 at CERN. The UHV requirements force the installation of ion pumps in the experimental areas of ATLAS. Due to the unacceptable particle background that standards ion pumps may generate, a reduction in the amount of material constitutive of the pump body is required. Hence, an stainless steel $0.8 \mathrm{~mm}$ thick body annular triode ion pump has been designed. A pumping speed of $\sim 201 / \mathrm{s}$ at $10^{-9} \mathrm{mbar}$ is provided by 15 pumping elements. Finite elements analysis and destructive tests have been performed in its design. Final vacuum tests results are shown.
\end{abstract}

1 VARIAN S.p.A., Leini, Italy

2 LAPP, Annecy-le-vieux Cedex, France

3 CERN, Accelerator Technology Division, Geneva, Switzerland

Paper presented at the 8th European Vacuum Conference 23 - 26 June 2003, Berlin, Germany

CERN

CH - 1211 Geneva 23

Switzerland 


\title{
Optimized annular triode ion pump for experimental areas in the LHC
}

\author{
M. Busso ${ }^{1}$, A. Chatelaine ${ }^{2}$, C. Girard ${ }^{2}$, D. Flakowski, S. Ivaldi ${ }^{1}$, J. Knaster ${ }^{3}$, \\ J-M. Laurent ${ }^{3}$, I. Monteiro ${ }^{2}$, A. Rossi $^{3}$, R. Veness ${ }^{3}$
}

\begin{abstract}
The LHC will be the world next generation accelerator to be operational in 2007 at CERN. The UHV requirements force the installation of ion pumps in the experimental areas of ATLAS. Due to the unacceptable particle background that standards ion pumps may generate, a reduction in the amount of material constitutive of the pump body is required. Hence, an stainless steel $0.8 \mathrm{~mm}$ thick body annular triode ion pump has been designed. A pumping speed of $\sim 201 / \mathrm{s}$ at $10^{-9} \mathrm{mbar}$ is provided by 15 pumping elements. Finite elements analysis and destructive tests have been performed in its design. Final vacuum tests results are shown.
\end{abstract}

1 VARIAN S.p.A.,10040 Leini (To), Italy

2 LAPP, 749941 Annecy-le-vieux Cedex, France

3 CERN, 1211 Geneva 23, Switzerland 


\section{Introduction}

The Large Hadron Collider (LHC) is the next accelerator being constructed on the CERN site. The LHC machine will mainly accelerate and collide $7 \mathrm{TeV}$ proton beams but also heavier ions up to lead. It will be installed in the existing $27 \mathrm{~km}$ circumference tunnel, about $100 \mathrm{~m}$ underground, that previously housed the Large Electron Positron Collider (LEP). There will be 4 big experiments operating in the LHC: ALICE, ATLAS, CMS and $\mathrm{LHCb}[1]$ whose vacuum systems will be coated with distributed Non-Evaporable Getters (NEG) [2] and provided with lumped sputter ion pumps for non getterable gas species such as methane. Around the interaction point where collisions take place the UHV requirements are stricter. The installation of a standard sputter ion pump inside the detectors to enhance the pumping is not possible due to the particle background that it would cause. The careful choice of materials and optimization of structures are the main engineering criteria in the experimental areas. Special requirements in ATLAS imply the installation of an optimized annular triode ion pump close to the interaction point (Figure 1).

\section{Vacuum justification}

The main sources of gas desorption from the beam vacuum chamber walls are photons (synchrotron radiation from the proton beam accelerated in a circular orbit), ions and electrons accelerated to the walls by the beam space charge. In particular, ions generated by beam-gas interactions desorb molecules which can in turn be ionized and accelerated to desorb gas. If the pumping speed is too low, this process could diverge leading to a pressure runaway [3]. Since the ionization rate is proportional to the beam luminosity (and therefore to current), the pumping system must be designed to guarantee vacuum stability. In the experimental regions, the whole of the beam pipe is deposited with a NEG coating, which provides distributed pumping for gas species like hydrogen, carbon monoxide and dioxide. Hydrocarbons are pumped with lumped ion pumps.

The ATLAS experimental vacuum chamber is composed of 5 cylinders: the central pipe of $58 \mathrm{~mm}$ inner diameter, increasing to 80 and $120 \mathrm{~mm}$ on the 2 sides of the interaction point. In this geometry, due to the limited conductance of the pipes, it was found that an 
ion pump on each side of the interaction point is necessary for vacuum stability at nominal and ultimate LHC beam current [4]. The position and pumping speed of the pumps are being optimized with respect to the pump size and mass.

\section{Pumping elements}

The pumping element is in a triode configuration with a cylindrical symmetry (figure 2). The anode is composed of 15 stainless steel cylindrical cells (1) (200 mm outer diameter and $25.4 \mathrm{~mm}$ high). The cells are spot welded in groups of 5, and each group is spaced to the other by a ceramic insulator (2). The three groups of cells are spot welded to an internal ring. The two cathodes are composed of 5 titanium strips (3) each, circularly bent with decreasing radius. Three stainless steel brackets (4) hold the strips in the correct position, maintaining them free to move in the case of thermal expansion. For the same reason the strips have a $4 \mathrm{~mm}$ cut along the circumference. The element is positioned inside the pump using three elastic brackets (5) in order to avoid the use of screws or welding. The electrical connection between the feedthrough and the element is guaranteed by a spring, that allows the compensation of mechanical tolerances and misalignments and avoids residual stresses on the feedthrough. The electrical feedthrough (Varian new standard) guarantees a complete corrosion free operation in a small and compact size [5].

\section{Pump body}

\subsection{Design and calculations}

The design of the pump body has to fulfill the requirements of the pump without creating cavity-like zones that might affect electromagnetically the beam and also minimize coupling impedances. In addition, the pump wall thickness is minimized to reduce the background generated (Figure 3). The electrical criteria are satisfied by an RF shield of diameter $58 \mathrm{~mm}$ (that allows the beam passage) and $0.8 \mathrm{~mm}$ thick. To allow an efficient pumping circular holes $5 \mathrm{~mm}$ diameter are drilled in it. A copper coating in the inner wall reduces the resistive impedance to acceptable values. 
The choice of material of the pump body is based on transparency criteria and mechanical performance at bake out temperatures. The material that best fulfills these requirements is beryllium [6]. However its high price, technological difficulties and safety issues reduces its use [7]. The higher transparency of aluminium compared with stainless steel $316 \mathrm{~L}$ suggested its initial consideration as pump body material. The weldable and high temperature resistant alloy AA 2219 was chosen. The properties of these materials can be seen in Table 1.

However, the use of AA 2219 would limit the bake out temperature to $250^{\circ} \mathrm{C}$ and hence reduce the pump performance.

Finite-element (FE) analysis shows that with pump body walls $0.6 \mathrm{~mm}$ thick, 1 bar of external pressure and the RF shield ( $0.6 \mathrm{~mm}$ thick stainless steel $316 \mathrm{~L})$ installed, the deflection of the walls will be $0.24 \mathrm{~mm}$ with a maximum stress of $130 \mathrm{MPa}$ at $300^{\circ} \mathrm{C}$ close to the feedthrough position. The buckling analysis yields the first buckling mode at 8.8 bar (Figure 4) [8]. However, the difficulties of machining the walls to $0.6 \mathrm{~mm}$ within the defined tolerances of $+0.1 \mathrm{~mm}$ and the non-linear buckling that local lack of tolerances might trigger led to a wall thickness of $0.8 \mathrm{~mm}$.

\subsection{Tests and calculation validations}

To validate the design, three pump bodies were fabricated by spinning. Mechanical tests with strain gauges were performed. Two strain gauges were placed close to the feedthrough position where the maximum stresses were expected. Limitations due to the pump geometry forced the placement of these strain gauges in a non-optimal position

(Figure 5). The tests were performed in a hydraulic pressure vessel with increasing differential pressure up to 5 bars. No plastic deformation was observed. The stresses measured at 5 bar are $249 \mathrm{MPa}$ for gauge 1 and 142 for gauge 2. These values are very close to the $272 \mathrm{MPa}$ of concentrated stresses that can be found with the FE analysis in the area close to gauge 1 position and the $\sim 150 \mathrm{MPa}$ in the zone where gauge 2 was positioned (Figure 6) [9]. 


\subsection{Magnets}

The required magnetic field in ATLAS will be supplied by a large superconducting solenoid magnet which is part of the experiment. Tests performed on a prototype of the pumping elements showed a pumping speed increasing with magnetic field up to $0.4 \mathrm{~T}$ [10]. Permanent magnets can be added locally if the pump needs to operate with the detector solenoid switched off.

\section{$5 \quad$ Pumping performance}

The pumping speed measurements were performed after bake out and saturation with the injection of 0.5 mbar $\cdot 1$ of $\mathrm{N}_{2}$ (Table 2). The permanent magnets used during the testing allowed a magnetic field of $0.09 \mathrm{~T}$. The pumping speed measured after the third bake out process was $\sim 18 \mathrm{l} / \mathrm{s}$ (figure 7 ), this value coincide with those obtained for $\mathrm{N}_{2}$ during the preliminary tests performed on a prototype [10] with a similar magnetic field. This means that each pumping element pumped with $\sim 1.21 / \mathrm{s}$.

The ultimate vacuum achieved after 3 bake outs and 4 days pumping was $1.3 \times 10^{-10}$ mbar. The application of an alternate high voltage of $8 \mathrm{kV}$ during 3 minutes allowed the reduction of the pump current to $\sim 100 \mathrm{nA}$.

\section{Conclusions}

The annular triode ion pump design is considered to have been validated after the tests performed. The pumping speed of $\sim 18 \mathrm{l} / \mathrm{s}$ is sufficient to allow dynamic vacuum values around the interaction point of ATLAS of the order of $10^{-10}$ mbar fulfilling the detector requirements. The optimization of the mass in the pump body minimizes the particle background and allows the physics detection in the experiment. The required magnetic field during operation will be provided by the superconducting solenoid magnet of the experiment, however permanent Sm-Co magnets have been designed to allow pumping, if needed, during experiment shutdowns.

\section{References}

[1] The LHC study group, The Large Hadron Collider, CERN/AC/95-05 
[2] C. Benvenuti et al., Vacuum 60 (2001) 57-65

[3] A. Mathewson, Vacuum problems associated with the next generation of hadron colliders, Maui, Hawai, November 3-9, 1994

[4] A. Rossi, ATLAS Technical Board Meeting 12 Dec. 2002

[5] D. Flakowski, Tests de nouveaux passages VARIAN, CERN Vac. Tech. Note 0217, EDMS : 353809

[6] R. Veness et al., Design of beam pipes for LHC experiments, Vacuum 64 (2002) $467-473$

[7] J. Knaster, Beam vacuum inside experiments, LHC days 2003 proceedings

[8] A. Chatelain, LAPP-Me-RE-002, CERN-LAPP collaboration LHC4

[9] I. Monteiro, LHC4-Me-CRE-002-01, CERN-LAPP collaboration LHC4

[10] D. Flakowski, Essais de pompes ioniques pour les expériences, CERN Vac.

Tech. Note 00-30 


\section{Figures}

Figure 1: Position of the triode annular ion pump inside ATLAS

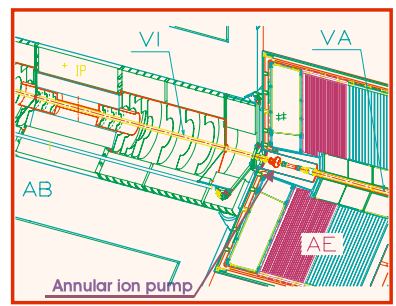

Figure 2: Pumping elements

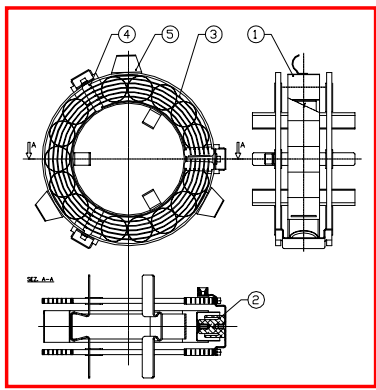

Figure 3: Annular ion pump components
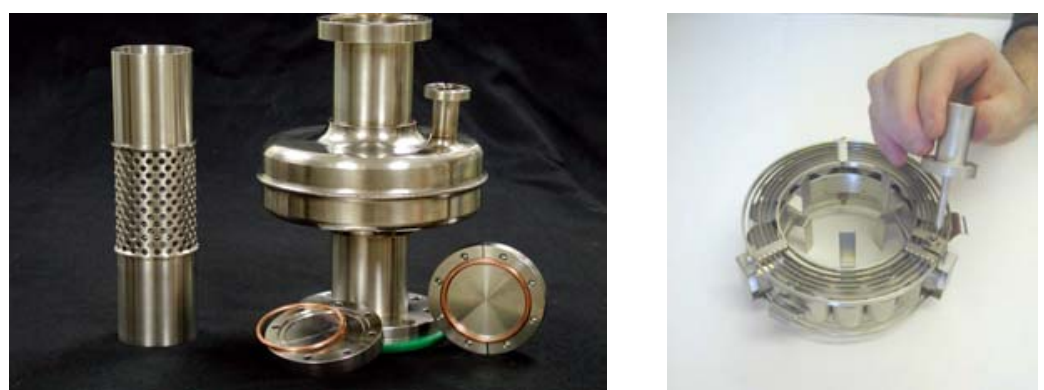

Figure 4: Stresses and buckling analysis on stainless steel 316L $0.6 \mathrm{~mm}$ thick
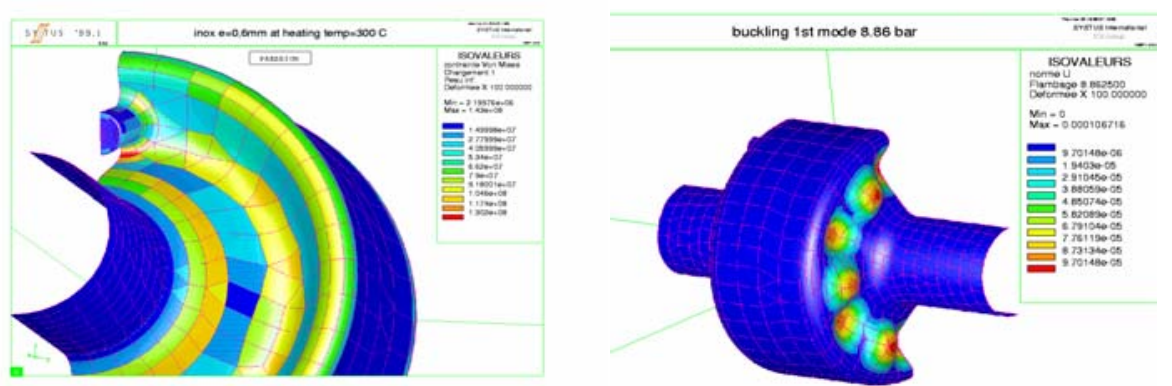

Figure 5: Strain gauges position

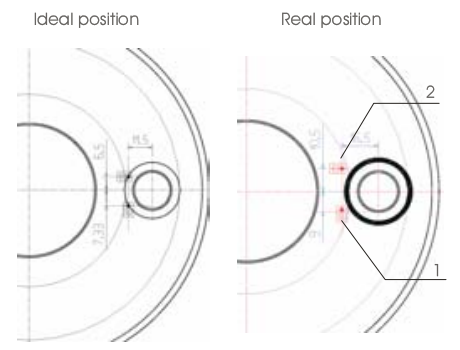


Figure 6: Stresses calculated with 5 bar of external pressure

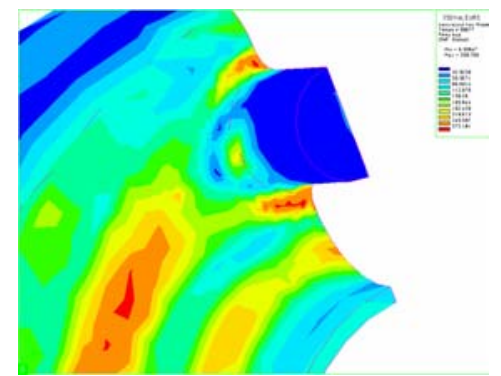

Figure 7: Pumping speed after three bake outs

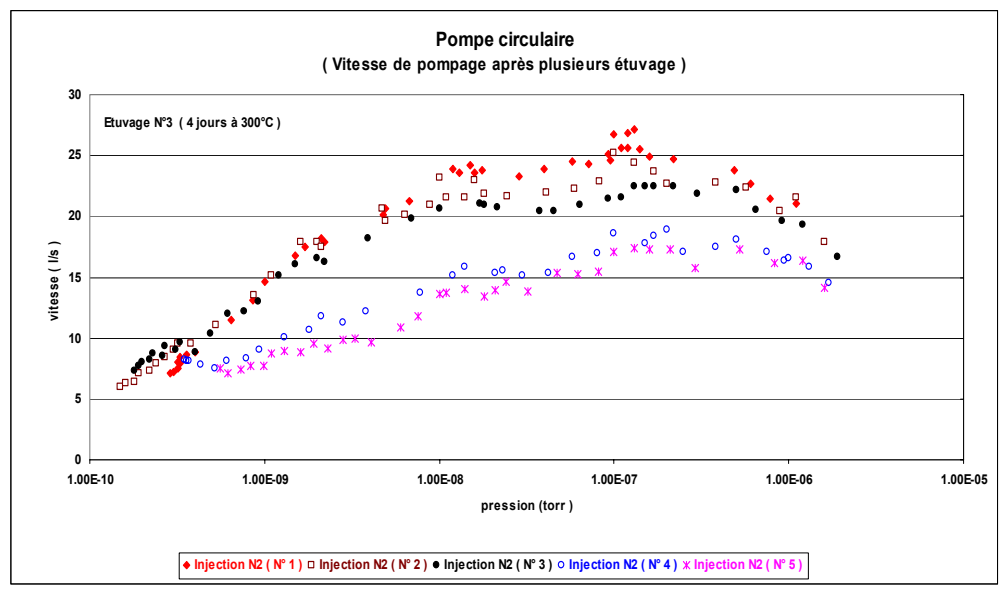

Table 1

\begin{tabular}{|l|l|l|l||}
\hline \hline & $E @ 20^{\circ} \mathrm{C}$ & $E @$ bake out $T$ & Rp $0.2 @$ bake out $T$ \\
\hline $316 L$ & $200 \mathrm{GPa}$ & $179 \mathrm{GPa} @ 300^{\circ} \mathrm{C}$ & $118 \mathrm{MPa} @ 300^{\circ} \mathrm{C}$ \\
\hline $2219 \mathrm{T6}$ & $73.5 \mathrm{GPa}$ & $66.5 \mathrm{GPa} @ 204^{\circ} \mathrm{C}$ & $172 \mathrm{MPa} @ 204^{\circ} \mathrm{C}$ \\
\hline
\end{tabular}

Table 2

\begin{tabular}{|c|c|c|c|c||}
\hline $\begin{array}{c}\text { Bake out } \\
\text { cycle }\end{array}$ & Baking time & $\begin{array}{c}\text { Baking } \\
\text { temperature }\end{array}$ & $\begin{array}{c}\text { Pressure } \\
\text { (mbar) }\end{array}$ & $\begin{array}{c}\text { Pump } \\
\text { current }\end{array}$ \\
\hline $1^{\text {st }}$ & $24 \mathrm{~h}$ & $180^{\circ} \mathrm{C}$ & $3.9 \times 10^{-9}$ & $\mathrm{I}=10 \mu \mathrm{A}$ \\
\hline $2^{\text {nd }}$ & $48 \mathrm{~h}$ & $300^{\circ} \mathrm{C}$ & $7.2 \times 10^{-10}$ & $\mathrm{I}=1 \mu \mathrm{A}$ \\
\hline $3^{\text {rd }}$ & 4 days & $300^{\circ} \mathrm{C}$ & $1.3 \times 10^{-10}$ & $\mathrm{I}=3 \mu \mathrm{A}$ \\
\hline
\end{tabular}

